\title{
Researches on Alloy form Characteristic Based on Gypsum Molding
}

\author{
Ziyu Zhao, Guangtao Zhou, Suzhi Zhang ${ }^{*}$ and Bibo Xiao
}

College of Mechanical Engineering and Automation, Huaqiao University, Xiamen, Fujian, 361021, China

\begin{abstract}
With the rapid development of economic, gypsum is widely used in casting and other industry areas. In this paper, the result is obtained that the performance of plaster mold is better when gypsum-water ratio is 0.5 . If the composition of gypsum slurry mixture ( $\alpha$-hemihydrate, mullite powder, zirconium powder, reinforcing fibers) is mullite powder: zircon flour: enhancing fiber $=1: 0.25: 0.2: 0.02-0.04$, the mixture will be optimum property. The temperature influencing on bending-strength of plaster and the influence of gypsum-water ratio, filler types and calcination temperature on gypsum bending-strength has been analyzed by means of experiments. Spiral-shaped gypsum mold was made by gypsum molding material and mobility experiment was conducted on $\mathrm{Pb}-\mathrm{Sn}$ alloys. Compared with pure gypsum, gypsum mixture had better mechanical properties. The fluidity of the alloy in the gypsum mold was effected by casting pressure, pouring temperature and alloy ratio. The research results have benefit to the application of gypsum casting technology.
\end{abstract}

Keywords: Gypsum mold, Bending strength, Pb-Sn alloy, Liquidity.

\section{INTRODUCTION}

Plaster casting is a modern method of precision casting and thin-walled complexity structure molding which is high in quality and precision, wide range in size and weight, short cycle of research and development. In the recent years, the development of liquid metal forming technology has made plaster casting technique widely used in many areas [1-3]. Therefore plaster is considered as the main material of gypsum plaster molds because its property is the linchpin of plaster mold process. A lot of researchers studied plaster raw materials and roasting process in order to improve the quality of plaster casting $[4,5]$. The complex of casting structure and quality of casting processes has brought a serious problem which need to be solved. Rejection rate will increase if the problem can't be solved properly. Increasing of liquid alloy filling capacity is one of the most effective ways. The fluidity of metals and alloys are important factors affecting the ability of filling [6-8]. By lots of experiments, various performance of gypsum and their mixture were analyzed in this paper. The liquidity property of $\mathrm{Pb}-\mathrm{Sn}$ alloy in gypsum mold was also investigated. The result offers good recommend for getting best gypsum mold and integrated alloy castings.

\section{2. a-HEMI HYDRATE GYPSUM}

$\alpha$-hemi hydrate gypsum $\left(\alpha-\mathrm{CaSO}_{4} \cdot 1 / 2 \mathrm{H}_{2} \mathrm{O}\right)$ also known as high-strength gypsum, after being mixed with water, it turns into a slurry with certain fluidity, when the slurry satisfies the requirement of flow, water absorption is usually in low level. Meanwhile, with hemi hydrate gypsum dissolving, hydrating and separating out gypsum, gypsum nuclei grow and crystals interleave into each other, them adhered, and

*Address correspondence to this author at the College of Mechanical Engineering and Automation, Huaqiao University, Xiamen, Fujian, 361021, China; Tel: +86-592-6162598; Fax: +86-592-6162599;

E-mail: zhangzhs@hqu.edu.cn cohered crystalline structure net and formed plaster harden body with a certain adhesiveness and cohere ness. Hence the products of $\alpha$-hemihydrate gypsum plaster have a certain density and strength to be applied in manufacturing of low absorption model and products.

As $\alpha$-hemi hydrate gypsum mixed with water, the amount of adding water has a great influence on the plaster strength. Generally, water-gypsum ratio is used to measure the performance. Water-gypsum ratio is defined as mass proportion of water and gypsum powder. Gypsum slurry flow properties are measured by the fluidity. Assay method is to place a sample cylinder $(\varphi 40 \mathrm{~mm} \times 50 \mathrm{~mm})$ on the glass plate, timing when starting stiring the pulp, filled slurry into cylinder about $3 \mathrm{~min}$, then, quickly removed the cylinder and measure the speed diameter after solidification. When watergypsum ratio being 0.5 , testing results of the slurry and main property of obtained products are shown in Table 1.

In this experiment, $\alpha$-hemi hydrates gypsum and water $\left(15^{\circ} \mathrm{C}\right)$ were mixed into the gypsum slurry by different proportions, then strips of plaster specimens $(120 \mathrm{~mm} \times 18$ $\mathrm{mm} \times 17 \mathrm{~mm}$ ) were made. After air-cooled for $24 \mathrm{~h}$, the results of bending strength performance tests were shown in Fig. (1).

The Fig. (1) showed that water-gypsum ratio had a great influence on the strength of plaster. With increasing of water-gypsum ratio, the fluidity of gypsum slurry improved, but the intensity decreased, and plaster could not meet the necessary requirement of strength. The optimal amount of mixed water of gypsum was determined by strength index, but it must ensure that besides meeting the requirement strength of gypsum, it must meet the requirement of the limit of fluidity also. The results showed that when water-gypsum ratio was 0.3 , it had high strength but poor mobility of gypsum slurry. Water-gypsum ratio 0.5 was more suitable when satisfies the minimum liquidity degree. 
Table 1. Main Performance of $\alpha$-Hemi Hydrate Gypsum

\begin{tabular}{|c|c|c|c|c|c|c|}
\hline $\begin{array}{c}\text { Initial Setting } \\
\text { Time } \mathbf{t}_{\mathbf{1}} / \mathbf{M i n}\end{array}$ & $\begin{array}{c}\text { Final Setting } \\
\text { Time } \mathbf{t}_{\mathbf{2}} / \mathbf{M i n}\end{array}$ & Fluidity $\mathbf{L} / \mathbf{m m}$ & $\begin{array}{c}\text { Density } \\
\boldsymbol{\rho} / \mathbf{g} . \mathbf{c m}^{-3}\end{array}$ & $\begin{array}{c}\text { Compressive Strength } \\
\boldsymbol{f}_{\mathrm{s}} / \mathbf{M p}_{\mathbf{a}}\end{array}$ & $\begin{array}{c}\text { Bending Strength } \\
\boldsymbol{f}_{\mathrm{ce}} / \mathbf{M p} \mathbf{p}_{\mathbf{a}}\end{array}$ & $\left.\begin{array}{c}\text { Expansion } \\
(\sim \mathbf{8 0 0}\end{array}{ }^{\circ} \mathbf{C}\right) \boldsymbol{\varphi} / \%$ \\
\hline 7 & 12 & $\varphi 80$ & 2.74 & 26 & 5.10 & -2.46 \\
\hline
\end{tabular}

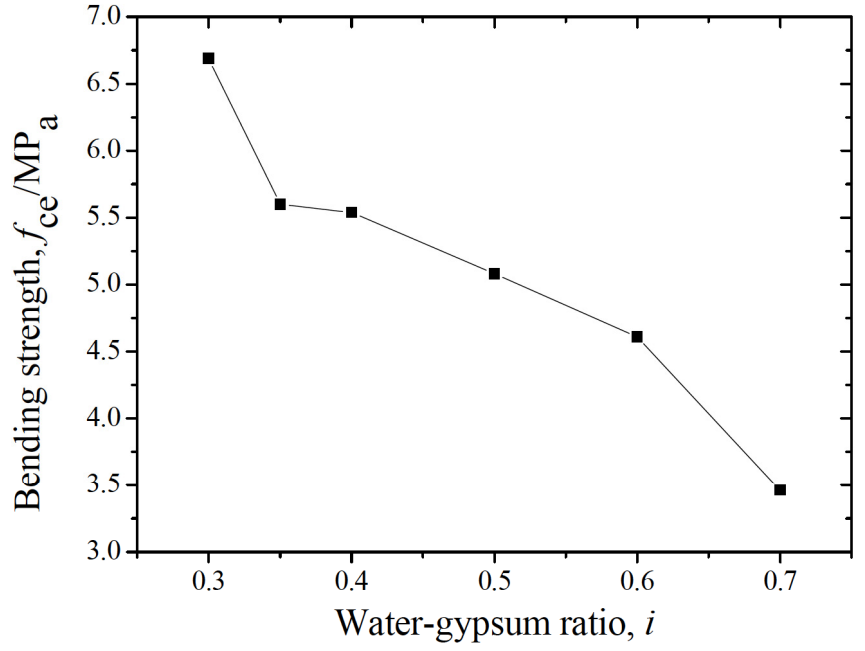

Fig. (1). Effects of the ratio of water and gypsum on bending strength of gypsum.

\section{3. $\alpha$-HEMIHYDRATE MIXTURE}

$\alpha$-hemi hydrate is seldom used to make gypsum mold alone because gypsum will dehydrate and phase change with volume accompanied in the baking process. So appropriate amount of filler must be added into gypsum powder to reduce the linear shrinkage and crack tendency of gypsum mold and improve the ability of the thermal conductivity of gypsum mold.

\subsection{Composition}

Mode of plaster and filler mixing belong to mechanical way, and they do not have an chemical reaction. Gypsum coating is as the bond, thus the strength relates to gypsum property, filler and plaster mosaic status as well as water quantity. Mixture strength was mainly ensured by gypsum membrane which is made up of wrapping filled and the plaster net. Many different types of fillers, including mullite powder, quartz powder, zirconium powder, bauxite, etc., is selected based on different performance requirements of the mixed plaster.

Mullite powder $\left(3 \mathrm{Al}_{2} \mathrm{O}_{3} .2 \mathrm{SiO}_{2}\right)$ has high melting point, chemical stability, low coefficient of linear expansion, resistance ability of thermal and cold shock. The mold would get increasing capacity of anti-shock heat and cool. But the quantity should be properly controlled else the crack of the sample would increase. Zircon powder $\left(\mathrm{ZrSiO}_{4}\right)$ has good thermal conductivity, small thermal expansion, high refractoriness, and could reduce the crack tendency, it also had a strong chilling effect on the casting to refine metal structure. As melting point $2430^{\circ} \mathrm{C}$, it has high temperature chemical stability, when heated in the air it is less susceptible to oxidation. The purpose of mix it with gypsum plaster is to reduce the crack tendency. Reinforcing fibers in these two ingredients mixed and plemented each other and mosaic closely, then the mixture of gypsum mold would have no crack tendency, which improved strength and made surface no scaling.

Based on the above purpose, plaster is used as based material, mullite powder, zircon powder and reinforcing fibers are used as filler.

\subsection{Performance}

The filler should have appropriate melting point, refractoriness, appropriate line of expansion, good chemical stability and dispersion suspension and so on. For the casting mold, each mold filling and the addition cannot be ignored. The ratio of cast mold material component need to meet the performance requirement. The amount of adding filler in experiment are 300 mesh zircon flour $15 \%-30 \%, 300$ mesh mullite powder $15 \%-30 \%, 2 \%-4 \%$ increase fiber. So the preliminary research in this paper which is based on the samples strength impact uses the orthogonal experimental optimizing the best ratio of filler: gypsum: mullite powder: zircon flour: enhanced fiber $=1: 0.25: 0.2: 0.021$.

The optimized results show that when slurry flow index is about $990 \mathrm{~mm}$, the specimen had no crack tendency. Due to complement of gypsum mixture components reinforcing each other, strength of plaster casts has improved and crack will tend to be disappeared. In this experiment, the mass fraction of reinforcing fibers is about $2.1 \%$. So strength of gypsum mixture increased while flow of slurry does not decreased.

\subsection{Impact Factors}

Parameters of roasting process was significant on the gypsum mold. In order to make good gypsum mold, cformula of a good combination property was chosen. The specimens made by c-formula and by pure gypsum respectively powder were roasted at the same temperature, then bending strength tests were conducted. The results were shown in Fig. (2). The results showed that calcinations temperature of pure gypsum is relatively narrow range, while gypsum mixture is in a wide temperature range. The temperature points of plaster mixture cast are higher than the same point of pure plaster cast, reflecting excellent performance of the mixed plaster.

At $300^{\circ} \mathrm{C}$, compared with pure gypsum specimens, gypsum mixture specimens had no cracks with the linear shrinkage rate of $4.5 \%$. Meanwhile, specimens of pure gypsum had severe cracks, surface loss, and $10 \%$ of linear shrinkage rate.

Calcinations temperature had great effect on the crack of pure gypsum due to high phase transition contraction and low thermal conductivity. When rapidly heated to $300^{\circ} \mathrm{C}$, the surface contracted sharply but inner layer still in expansion so that it was easy to appear crack or surface abscission. It was easy to draw off when rapid cooling. The bending 
strength of the gypsum mixture added by filling performs better at the same temperature. When temperature was $50^{\circ} \mathrm{C}$ $-60^{\circ} \mathrm{C}$, the mold had the optimum performance. If the temperature reached to $700^{\circ} \mathrm{C}$, mold still had no crack (Fig. 3).

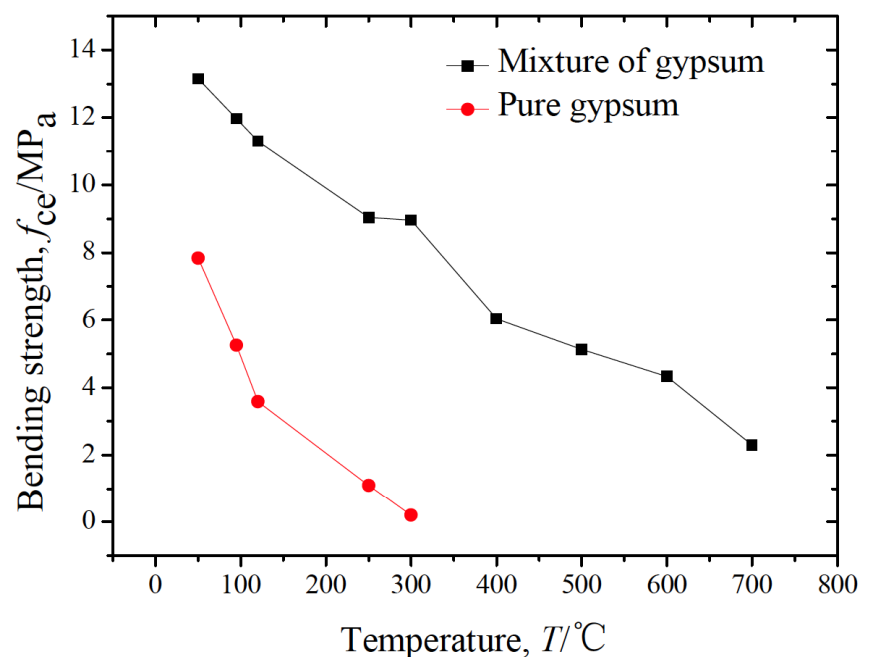

Fig. (2). Effects of temperature on bengding strength.

\section{MOLD MANUFACTURE}

Spiral-shaped mold is used in order to test the alloy flow in plaster mold. It transition of conversion in helix rubber mold. Rubber mold surface need degreasing, cleaning, drying, and spraying release agent. First ensure a clean surface and good surface characteristics, then ensure the quality of the transition and improve the gypsum mold precision. Fig. (4) shows the rubber mold by the pretreatment.

(a) Pure gypsum

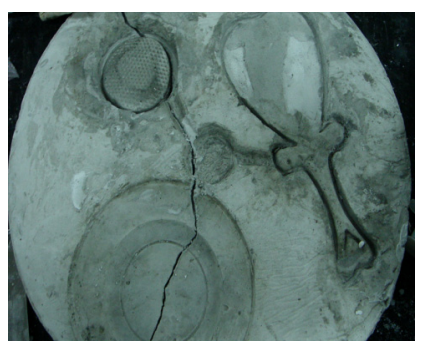

Fig. (3). Mould of pure gypsum and mould of gypsum mixture.

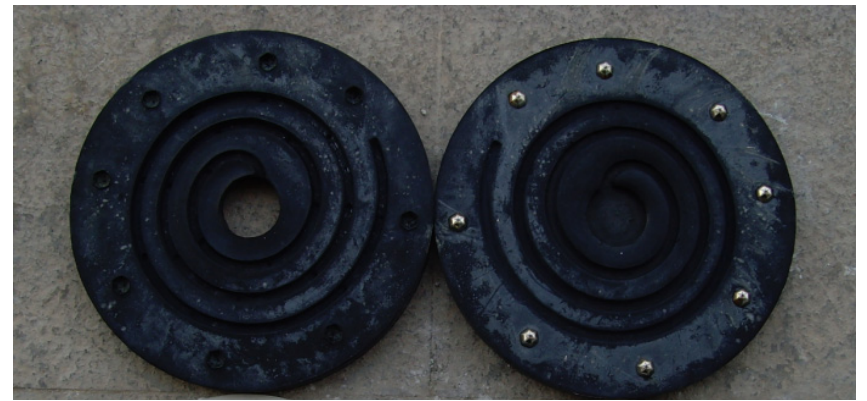

Fig. (4). Spiral rubber mold.

In order to transform rubber mold to gypsum mold, the transition soft mode was used. Transitive soft mode of silicone rubber was prepared by silicone rubber which is of good elasticity, copying, flexibility. Basically it will accurately replicate the appearance and does not lose accuracy in the convey processing, but the crux is that we must choose silicone rubber material with smaller shrinkage, moderate hardness and good strength. The transition of soft silicon rubber mold is shown in Fig. (5).

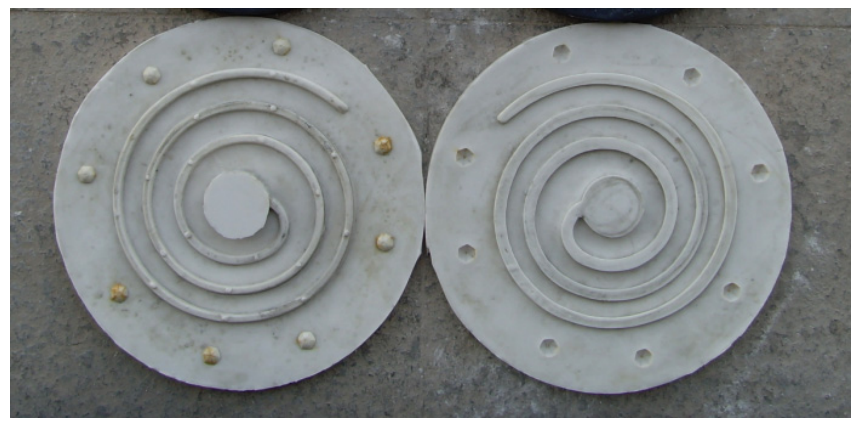

Fig. (5). Soft mold of silicone rubber.

Gypsum slurry prepared in the condition of vacuum was made by water and gypsum mixture. Grouted into transitive soft mode, the mold was got after hardening for 10-15 min and cooling for 24 hours. After that it was taken out immediately after drying for 50 minutes in the oven at $100^{\circ} \mathrm{C}$. Fig. (6) showed the spiral plaster mold for experiment. (a) Upper die

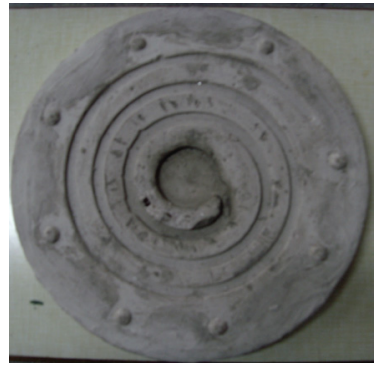

(b) Bottom die

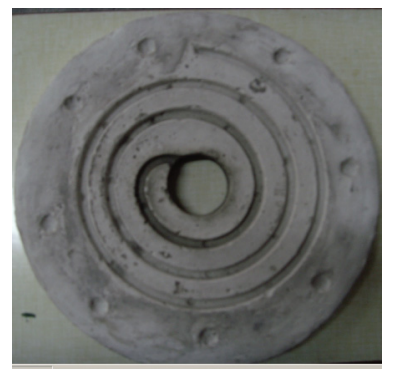

Fig. (6). Spiral gypsum mold.

\section{ALLOY FLUIDITY}

Experiment using tin-lead alloy as casting alloy was carried out in HW02 Centrifugal Casting Machine in two filling pressure, centrifugal force and gravity.

\subsection{Alloy Flow Test}

Spiral-shaped plaster mold would be fixed into centrifuge at several times, then a certain amount of alloy with the different temperatures and different proportions were poured into centrifuge to fully fill casting mode in centrifugal force or gravity. The samples were taken out after cooling the mold and then the length of the spiral line of the samples were measured. Measurement results were shown in Table 3. Fig. (7) was the typical sample corresponding to the number in Table 3.

\subsection{Results and Analysis}

The length of spiral sample in experiment indicated the main factors affecting performance of alloy flow include chemical composition, pouring temperature and pouring methods of alloy. Experiment results showed: (i) the liquidity of eutectic alloy was better than liquidity of noneutectic alloy. (ii) Alloy of higher temperature had good liquidity. (iii) fluidity of the alloy in centrifugal casting was 
(a) No. 1 specimen

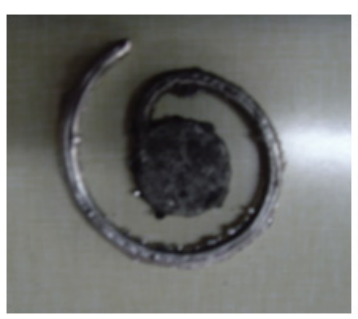

(b) No. 5 specimen

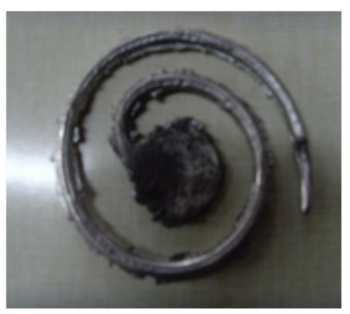

(c) No. 7 specimen

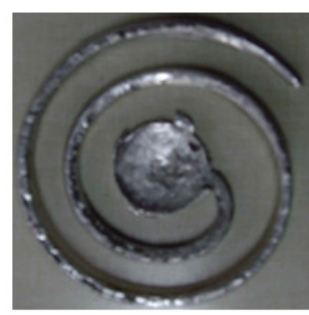

(d) No. 8 specimen

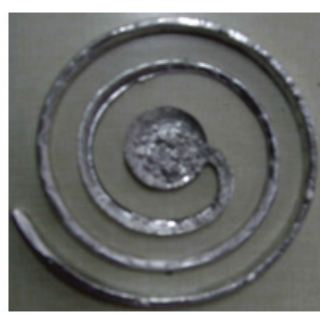

Fig. (7). Spiral sample.

better than that in gravity casting in the condition of invariant circumstances. Eutectic alloy is preferred as the raw materials of alloy casting production. Good quality and perfect shape was obtained by increasing pouring temperature and casting pressure in the course of pouring.

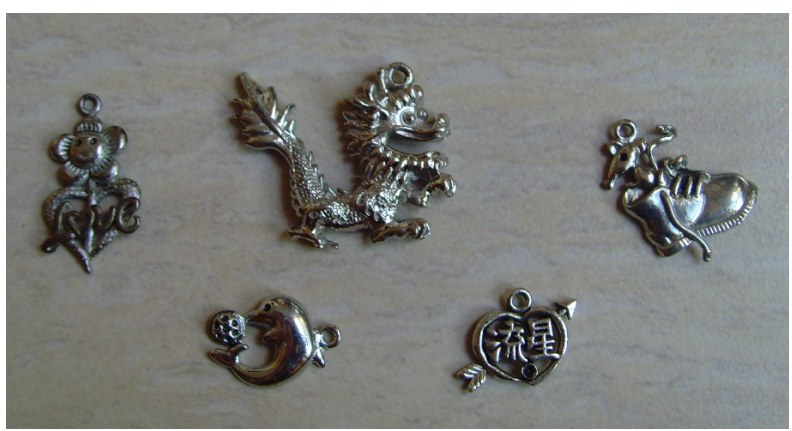

Fig. (8). Craft parts.

\section{CONCLUSIONS}

When the ratio of water-gypsum was $0.5, \alpha$-hemihydrates gypsum not but also satisfied the limit of fluidity only made the gypsum molds bending strength stronger. $\alpha$-hemi hydrate gypsum was used as initial material that added by highquality filler (zircon flour, mullite powder and reinforcing fibers, etc.). So the mold would have a combination property of lower thermal expansion, higher capacity of crack and higher bending strength.

Liquidity of $\mathrm{Pb}-\mathrm{Sn}$ alloy in the cast was restricted by many factors such as alloy ratio, casting pressure and pouring temperature. For eutectic composition alloy, high casting pressure and appropriately increasing of pouring temperature would help improving alloy liquidity and get complete casting.

\section{ACKNOWLEDGEMENTS}

This research is supported by the Nature Science Foundation of Fujian Province (2009J01254), and supported by the Invention Foundation of Fujian Development and Reform Commission (20061095), and supported by the Fund Project of Youth Innovation in Fujian Province (2006 F3084), respectively and experimental teaching reformation and building subject project in Hua Qiao University

Table 2. Sn-Pb Alloy Chemical Composition and Properties

\begin{tabular}{|c|c|c|c|c|c|c|c|}
\hline \multicolumn{2}{|c|}{ Chemical Composition/(Concentration, \%) } & \multirow{2}{*}{$\begin{array}{l}\text { Density/ } \\
\mathbf{g} \cdot \mathbf{c m}^{-3}\end{array}$} & \multicolumn{2}{|c|}{ Melting Temperature $/{ }^{\circ} \mathrm{C}$} & \multirow{2}{*}{$\begin{array}{c}\text { Tensile } \\
\text { Strength/MP }\end{array}$} & \multirow{2}{*}{ Elongation/\% } & \multirow{2}{*}{$\begin{array}{c}\text { Linear Expansion } \\
\text { Coefficient/ } \\
\times 10^{-6} \cdot{ }^{\circ} \mathrm{C}^{-1}\end{array}$} \\
\hline $\mathbf{P b}$ & Sn & & Solidus & Liquidus & & & \\
\hline 10 & Margin & 7.57 & 183 & 220 & 43 & 25 & 26 \\
\hline 38 & Margin & 8.35 & 183 & 183 & 41 & 34 & 24.7 \\
\hline
\end{tabular}

Table 3. Tin-Lead Alloy Liquidity in the Cast

\begin{tabular}{|c|c|c|c|c|c|}
\hline Ratio of Alloy & Casting Method & $\begin{array}{l}\text { Rotate Speed } / \\
\text { r. Min }\end{array}$ & Casting Temperature $/{ }^{\circ} \mathrm{C}$ & No. & Flow Length $/ \mathrm{mm}$ \\
\hline \multirow{4}{*}{$\begin{array}{c}\mathrm{Sn}-10 \% \mathrm{~Pb} \\
\text { (Hypoeutectic alloy) }\end{array}$} & \multirow{2}{*}{ Gravity } & \multirow{2}{*}{0} & 250 & 1 & 102 \\
\hline & & & 350 & 2 & 194 \\
\hline & \multirow{2}{*}{ Centrifugal force } & \multirow{2}{*}{60} & 250 & 3 & 257 \\
\hline & & & 350 & 4 & 337 \\
\hline \multirow{4}{*}{$\begin{array}{c}\mathrm{Sn}-37 \% \mathrm{~Pb} \\
\text { (Eutectic alloy) }\end{array}$} & \multirow{2}{*}{ Gravity } & \multirow{2}{*}{0} & 250 & 5 & 196 \\
\hline & & & 350 & 6 & 265 \\
\hline & \multirow{2}{*}{ Centrifugal force } & \multirow{2}{*}{60} & 250 & 7 & 415 \\
\hline & & & 350 & 8 & 655 \\
\hline
\end{tabular}




\section{REFERENCES}

[1] Kim K D, Yang D Y, Jeong J H. Plaster casting process for prototyping of die casting based on rapid tooling. Int J Adv Manuf Technol 2006; 28: 923-9.

[2] Sin S Lun, Dubé D, Tremblay R. Interfacial reactions between AZ91D magnesium alloy and plaster mould material during investment casting. Mater Sci Technol 2006; 22: 1456-63.

[3] Kanouni A, Saber D, Samdi A, Daoudi A, Moussa R, Gomina M. A study of plaster moulds degradation. Key Eng Mat 2004; 264268: 1589-92.

[4] Liu H J, Li Y M, Hao Y. Hot. Rapid Precision Casting Process Combining SLA Prototype With Plaster Casting. Hot. Work. Technol 2005; 13: 47-50. In Chinese.
Kalantar M, Moshtaghioun B M, Monshi A. Developing two new tundish plasters and comparing with the magnesia plaster used in continuous casting of steel. J Mater Eng Perform 2010; 19: 237-45.

[6] Baek J K, Kwon H W. Effect of squeeze cast process parameters on fluidity of hypereutectic Al-Si alloy. J Mater Sci Technol 2008; 24: 7-11.

[7] Ravi K R, Pillai R M, Amaranathan K R, Pai B C, Chakraborty M. Fluidity of aluminum alloys and composites: A review. J Alloys Compd 2008; 456: 201-10.

[8] Piccardo P, Amendola R, Adobati A, Faletti C. Study of the fluidity of copper-base alloys. Metall Ital 2009; 101: 31-8.

Received: August 28, 2010

Revised: November 26, 2010

Accepted: December 22, 2010

(C) Zhao et al.; Licensee Bentham Open.

This is an open access article licensed under the terms of the Creative Commons Attribution Non-Commercial License (http://creativecommons.org/licenses/by$\mathrm{nc} / 3.0 /$ ) which permits unrestricted, non-commercial use, distribution and reproduction in any medium, provided the work is properly cited. 